Canadian Oncology

Nursing Journal

Revue canadienne

de soins infirmiers

en oncologie

Volume 27, Issue 4 • Fall 2017

elSSN: 2368-8076 


\title{
Adapting and applying the Synergy Model on an inpatient hematology unit
}

\author{
by Yayra Amenudzie, Georgia Georgiou, Enoch Ho and Elizabeth O'Sullivan
}

\begin{abstract}
A pilot project was undertaken by an inpatient hematology and hematopoietic stem cell transplant unit to determine the feasibility of adapting the Synergy Model (Curley, 2007; 1998) to this patient population. During phase one, a patient characteristic tool for measuring complexity, stability, predictability, and participation in care was developed and tested. The tool was found to have strong face validity, high internal consistency, strong construct validity, and moderate inter-rater agreement. A nurse competency assessment was also developed, along with processes for making nursing and Health Care Aid assignments, as well as staffing decisions. The results of the pilot demonstrated that the Synergy Model can be adapted to this population and that it is feasible to use the model in an acute inpatient setting.
\end{abstract}

\section{BACKGROUND AND PURPOSE}

The malignant hematology/Hematopoietic Stem Cell 1 Transplant (HSCT) inpatient unit at the Juravinski Hospital underwent a transformational change that brought together two clinical teams, equipment, and support services. While the transition was successful on several fronts, the large physical footprint of the unit, the high patient acuity, the large number of novice nurses, different nursing practices between the two clinical teams, and limited Health Care Aid (HCA) resources (one HCA per shift for 39 patients), proved to be extremely challenging when it came to making

\section{ABOUT THE AUTHORS \\ Yayra Amenudzie, RN, MN, CON(C), Hematology Nurse \\ Georgia Georgiou, BA, MEd, Clinical Manager, Stem Cell Transplant Program \\ Enoch Ho, MPh, RPT, RAcu, Quality \& Value Improvement Office; hoenoch@HHSC.CA, T: 905.521 .2100 ext. 42097 \\ Elizabeth O'Sullivan, RN, BScN, MScN, Director, elizabethosullivan29@gmail.com \\ Address for correspondence: Georgia Georgiou, BA, MEd, and Yayra Amenudzie, RN, MN, Ron and Nancy Clark Hematology Unit, Juravinski Hospital and Cancer Centre, Hamilton Health Sciences, 699 Concession Street, Hamilton, ON L8V 5C2}

(905) 521-2100 ext 43910

E-mail: georgg@hhsc.ca or amenudzie@hhsc.ca

DOI: $10.5737 / 23688076274338342$ nursing and HCA assignments. There was inconsistency in how assignments were made from one shift to the next, which was causing friction among team members, complaints about workload, and unsafe assignments that put both patients and staff safety at risk. The high nursing workload, patient acuity, and a very heterogeneous nurse competency were negatively affecting teamwork, morale, the quality of patient care, patient and staff satisfaction, recruitment, and retention. The team identified the need to improve the work environment by developing an objective staffing decision-making model that takes into consideration not only the acuity of patients, but also the competency of the nurse.

A mandatory nurse-to-patient ratio or patient classification systems have been proposed, as approaches to ensure adequate nurse staffing. However, a literature review found that a method of staffing that incorporates unit nurses' direct input into daily staffing decisions is warranted, as there are many variables that impact daily staffing decisions (Hertel, 2012).

This observation led our team to pilot the Synergy Model for a number of reasons. First, the Synergy Model is a nurse-driven professional practice model that empowers nurses by enabling them to have control over their practice and work environment (MacPhee, 2011). Secondly, the model focuses on the patient's needs when determining the nurse competency requirements and resources requirements. Although the model originated in an acute and critical care setting, it has been applied in diverse settings and for multiple purposes. Published research suggests the model has the potential to transform the way healthcare providers think about patients and the method for making patient assignments. It provides a means for care providers to determine their patients' needs and the healthcare provider best suited to meet those needs, so that the best possible outcomes for the patients are achieved. While the Synergy Model has been shown to be beneficial in various healthcare settings with different patient populations (Carter \& Burnette, 2011; Pope, 2002; Gralton \& Brett, 2012; Kaplow \& Reed, 2008), we were unable to find any applications of the model in a Canadian inpatient hematology and stem cell transplant unit.

The purpose of the pilot project was to examine the feasibility of adapting the Synergy Model to make nursing assignments in a hematology/ oncology patient population and to evaluate its usefulness and impact. This paper focuses on the first phase of the pilot, which involved answering three questions: Can the Synergy Model be adapted for a hematology patient population? Is it possible to implement the model in an acute inpatient setting? What challenges are encountered and what strategies facilitate successful implementation? The second phase of the pilot, which is described elsewhere, involves an evaluation of the model's usefulness and impact on care delivery and practice. 


\section{METHODS}

A Synergy Work Group was formed to lead the pilot. The work group consisted of five registered nurses, a nurse practitioner, an HCA, the unit Clinical Educator, a Clinical Manager, the Program Director, a Quality Specialist, an Interprofessional Practice Chief, ad hoc input from physicians, and executive sponsorship from the Vice President of Interprofessional Practice and Chief Nursing Executive. Funding from two grants was obtained to enable a front-line nurse to have dedicated time to lead the project as a Synergy Coach. The Provincial Nursing Workload Project Resource Toolkit, which describes the British Columbia Nurse's Union (BCNU) use of the synergy model (BCNU, 2010), was also used as a guide.

This study used a Participatory Action Research (PAR) approach in which qualitative, as well as quantitative methods were used. The aforementioned Synergy Work Group actively participated in the development of the tool and the implementation process. Monthly group meetings were held with this core group to analyze the data collected from interviews, focus groups and surveys. One exit interview was held with the unit leader who led the implementation. Five hundred and sixty-eight nursing surveys, as well as 73 Unit Leader surveys were completed and were analyzed using statistical measures to ascertain reliability, validity, consistency and significance. Staff members were invited to complete a survey of the work environment prior to the start of the pilot. Common themes were extracted from the focus groups, surveys and interviews.

The section below outlines the methodology used to 1) assess the current state of the work environment, 2) develop and validate a patient characteristic tool for our patient population, 3) develop a nurse competency assessment for oncology nurses specializing in hematology and stem cell transplantation, 4) develop staffing guidelines, and 5) evaluate whether the tools and processes can be implemented.

\section{Instrument Development: Patient Characteristics Tool}

Our environmental scan highlighted the importance of developing tools and processes that were simple and efficient to use in daily practice. The work group used a Socratic, consensus-based decision-making process to generate patient markers that defined each of the eight patient characteristics for haematology. The group reviewed each marker and flagged those that appeared under more than one patient characteristic. These markers were then aligned with the most appropriate patient characteristic. The final "best" characteristics that were felt to reflect our patient's needs were selected. In order to simplify the tool, the work group chose to use a three-point rating scale instead of a five-point scale, with level 1 representing the most acute and level 3 being the least acute. Finally, the work group also chose to report each individual score for each characteristic rather than compute an average score as described in the original model.

To assess the face validity of the tool, three clinical experts (hematologists) reviewed the tool and provided feedback on how well each marker aligned with each patient characteristic and whether any markers or characteristics were missing or unnecessary. The physicians had no involvement in developing the tool and no familiarity with the Synergy Model. The tool was applied to real case studies to further assess face validity.

To test the construct validity of the tool, two hematologists who were unfamiliar with the Synergy Model, were asked to rate patients under each characteristic during their rounds, using a five-point scale. They based their ratings on their routine patient assessment and clinical judgment. At the same time, an expert nurse rated the same patients separately from the physicians. The physician and nurse were blinded to each other's assessment results and their results were compared using the Pearson Correlation test.

Lastly, the internal consistency and inter-reliability of the tool were also determined using Cronbach's Alpha and Intra-Class Correlation (ICC) test, respectively. The inter-reliability of the tool was tested by having three expert hematology nurses independently rate the same patients while being blinded to each other's ratings.

\section{Instrument Development: Nurse Competency Assessment}

A nurse competency assessment was developed based on Benner's model (1984), the Canadian Association of Oncology Nurses standards (2002), as well as the nurse characteristics outlined in the Synergy Model (Curley, 2007). All hematology nurses completed the self-assessment and were categorized as novice, advanced beginner, competent, proficient, or expert.

\section{Process Development: Assignments \& Staffing Guidelines}

Guidelines for making the nursing assignments did not exist in our unit and needed to be developed. The guidelines needed to specify the type of patients (level of acuity) and the number of patients a nurse can be assigned, based on the nurse's competency. Given the fluctuating acuity of hematology patients and the need for increased monitoring and nursing interventions, it was evident that there would be times when additional resources would be needed in order to meet the staffing guidelines. Senior leadership approval and backing was obtained for the development of criteria to be used for requesting additional nursing and/or HCA resources, based on patient acuity scores.

To develop the staffing guidelines, nurses were asked to complete a survey on every day shift for three weeks, which involved rating their assignment as a) ideal work pace enabling them to go above and beyond, b) busy but manageable, c) busy and barely manageable, or d) unmanageable and unsafe. They were also asked to indicate whether the acuity scores reflected the actual acuity of the patient and to record their level of nurse competency. A similar process was used to develop staffing guidelines for assigning the HCA. These data were then used to develop guidelines for making assignments and for defining the thresholds for additional staffing.

Two focus groups provided input on how to design the daily operational processes for scoring patients, submitting the scores, updating the scores, making the assignments, and for requesting additional resources. The sampling for the two focus groups was purposeful and included nurses from each nursing rotation. Staff education on the tools and processes 
was provided through educational retreats and one-to-one coaching. It was decided that patients would only be scored on day shifts during the pilot to ensure the necessary supports were in place to facilitate successful implementation.

\section{Methods for Evaluating the Model's Applicability}

The following measures were selected to determine whether the newly developed tools and processes could be applied: a) percentage of time the patient acuity tool was completed by nurses, b) percentage of time the patient acuity scores and staff competencies were used to make the nursing assignment, c) how often the criteria were met for increasing staffing levels, and d) barriers and enablers to implementation. These data were collected over 73 day shifts, from January 13 , 2014-March 31, 2014, and were obtained using a daily nurse survey, daily unit leader survey, focus groups, and a 1:1 interview with the Unit Leader.

\section{RESULTS}

In total, 568 nursing surveys, 73 Unit Leader surveys, staff comments from two focus groups, and one interview with the Unit Leader were collected and analyzed. The results are discussed, as they relate to each of the pilot project questions.

\section{Question 1: Can the model be adapted for hematology patients?}

A hematology patient acuity tool was developed for our patient population comprising four characteristics: participation in care, predictability, complexity, and stability (See Figure 1).

The hematology experts agreed on the four characteristics and the markers within each characteristic, indicating strong face validity. An analysis of the data obtained from the daily nursing survey indicated that $94 \%$ of nurses felt that the synergy scores accurately reflected patient acuity. The results of the internal consistency test revealed a Cronbach Alpha of greater than 0.88 for all four patient characteristics (complexity $=0.89$; stability $=0.95$; participation in care $=0.89$; predictability $=0.87$ ). This suggests that all items consistently measure the underlying construct, and they all offer something unique.

The tool was also found to have good construct validity. The Correlation Coefficients for each domain were Complexity $=.72$; Predictability $=.77$; Participation in care $=.75$; Stability $=0.54$. The results for the inter-rater reliability test of the tool using ICC were greater than 0.7 for all characteristics, indicating substantial to almost perfect agreement between raters $($ Complexity $=0.81$; Stability $=0.92$; Participation in care $=0.77$; Predictability $=0.71$.

\section{Question 2: Can the model and processes be applied?}

The tools and process were applied consistently, the majority of the time. RNs used the synergy patient characteristics tool to score patients $77 \%$ of shifts and the Unit Leader used the scores to make the assignment $100 \%$ of shifts. An additional HCA was needed for 27 shifts and an additional registered nurse was needed on 23 shifts. However, it was not always possible to increase staffing when needed because staff were either unavailable or overtime costs would be incurred.

\section{DISCUSSION}

\section{Limitations of the model}

The model is designed to measure patient acuity, not workload. However, workload must also be considered when making the assignment. One drawback of changing the acuity scale from a five-point scale to a three-point scale is that the tool is less sensitive in picking up differences that affect workload. For example, two patients may have the same scores, but require different nursing interventions that take more or less time. The tool could be improved by capturing interventions that require closer monitoring and nursing care.

Although the Synergy Model provides a more objective way for making the nursing assignment, the process is time-consuming, complex and intimidating. It requires synthesizing four scores for 39 patients and consideration of other factors (e.g. continuity of the assignment, geography, etc.). Having a consistent Unit Leader for six to eight months provided the opportunity for ample practice. Adequate training is also needed to enable nurses to become confident in making assignments using the synergy scores.

Achieving compliance with daily scoring and updating scores when acuity changes requires constant reinforcement and is possible with the right prompts and accountability structures in place. To achieve a good match between patient needs and nurse competency, it is necessary to have an appropriate nursing skill set on every shift with a sufficient cross-section of competent, expert, and proficient nurses. When there is a disproportionate number of novice and advanced beginners in a rotation, it is difficult to meet the staffing guidelines. Nonetheless, the model can help inform recruitment decisions, optimal configuration of the master rotation, and nursing professional development planning. Finally, if the model is to be used to make staffing adjustments, leadership support and budget must be obtained up-front and a large enough pool of part time on-call staff is needed in order to avoid incurring overtime costs.

\section{Enablers for Implementation}

The responses from the focus groups, surveys, and interviews pointed to several enablers that facilitated successful implementation: a) backing and sponsorship from the hospital's senior leadership; b) strong project management and a clear plan to stay on track and on budget; c) access to funding that enabled a front-line nurse to lead the pilot and to engage front-line staff; d) having a Unit Leader with strong leadership skills; e) access to Quality Specialists, Practice Chiefs, and experienced researchers for guidance and mentorship; f) access to funding to support staff education on the new tool and processes; g) frequent auditing of data to ensure data integrity; and $h$ ) process in place to regularly update $\mathrm{RN}$ competencies.

\section{CONCLUSION}

The results of our pilot project affirm that the Synergy Model can be adapted to different patient populations, as purported by others (MacPhee et al., 2011; Kaplow \& Reed, 2008; Kerfoot et al., 2006; MacPhee et al., 2010). The application of 
Figure 1. C4 Hematology Patient Acuity Tool

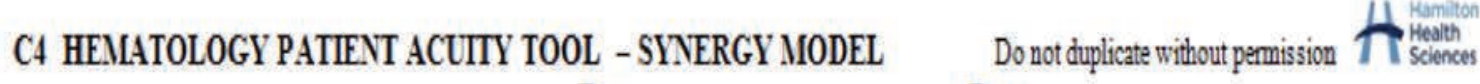

Name $\mathrm{Rm}$ Date

Please Refer to the "Defined Terms section" for any words with an asterisk "(Defined terms avalable on share drive or laminated form found on cork board at each station).

Level $1 \rightarrow$ Highly acute Level $2 \rightarrow$ Moderately acute

Level $3 \rightarrow$ Least acute

*We are scoring patients to reflect their current needs unless it explicitly states "next shift".

* Palliative* patients: do not need to be scored under stability.

\section{A-STABLITY}

\begin{tabular}{|c|c|c|}
\hline $\begin{array}{l}\text { Lerel l(at least } 2 \text { of the } \\
\text { criteria; if one criteris only } \\
\text { then pt is lerel } 2 \text { ) }\end{array}$ & $\begin{array}{l}\text { Lerel 2 (at least } 2 \text { of the } \\
\text { criteria OR only one in } \\
\text { level } 1 \text { and one in level 2) }\end{array}$ & Lerel 3 \\
\hline DActvaly blexding" & 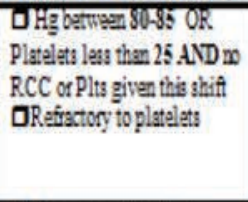 & 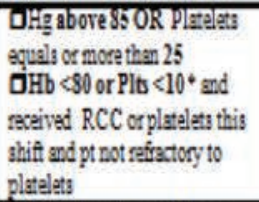 \\
\hline $\begin{array}{l}\text { D.More then } 2 \text { la value? } \\
\text { imbalances requifing } \\
\text { interventions not including } \\
\text { blood products trensfusions }\end{array}$ & $\begin{array}{l}\text { DOna or two lab valus" } \\
\text { imbalsucas requing } \\
\text { intervention not including } \\
\text { blood products transfusions }\end{array}$ & 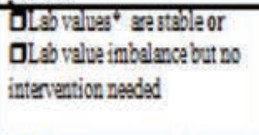 \\
\hline $\begin{array}{l}\text { DNeutroparic and } \\
\text { Tempeaturemore then } 38\end{array}$ & 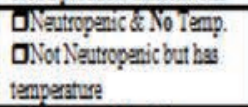 & $\begin{array}{l}\text { DNoNeutroperia and } \mathrm{No} \\
\text { temperatue }\end{array}$ \\
\hline $\begin{array}{l}\text { ONew" onset of unatable } \\
\text { vitals* and requining } \\
\text { interventions (vitals not } \\
\text { vithin pt's nom; excluding } \\
\text { temp.) }\end{array}$ & $\begin{array}{l}\text { QVitals" stable with } \\
\text { interventions ( } Q_{2} \text { included) } \\
\text { atinstable vitals }{ }^{4} \text { with } \\
\text { ongoing monitoring and } \\
\text { intervation }\end{array}$ & $\begin{array}{l}\text { OWrala stable, } \alpha \text { within } \\
\text { patient's nom. No interverioss } \\
\text { required }\end{array}$ \\
\hline $\begin{array}{l}\text { QVoD or flud orelos" } \\
\text { satining } 2 \text { or }>\text { interventions }\end{array}$ & 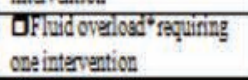 & $\begin{array}{l}\text { ONo flud over loed ORno } \\
\text { intervations naedad }\end{array}$ \\
\hline 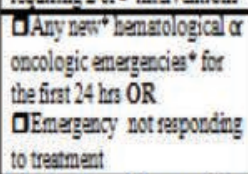 & $\begin{array}{l}\text { DAryidantfied } \\
\text { bematological or oncologic } \\
\text { emergencies" which is } \\
\text { improving on trestment }\end{array}$ & $\begin{array}{l}\text { o. No bematological or } \\
\text { oncologic energencias" }\end{array}$ \\
\hline $\begin{array}{l}\text { DAlted cogration requifing } \\
\text { 1:1 }\end{array}$ & $\begin{array}{l}\text { DAltered cogrition butesaly } \\
\text { redireted }\end{array}$ & 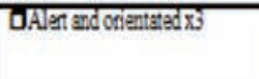 \\
\hline
\end{tabular}

\begin{tabular}{|c|c|c|}
\hline \multicolumn{3}{|c|}{ D-PARTICIPATION IN CARE* } \\
\hline $\begin{array}{l}\text { Lerel } 1 \text { (at least } 2 \text { criteria; } \\
\text { if only } 1 \text { then pt is level } 2 \text { ) }\end{array}$ & $\begin{array}{l}\text { Lerel 2(at least } 2 \text { of the } \\
\text { criteria) }\end{array}$ & Level 3 \\
\hline $\begin{array}{l}\text { DPt unable to pertom ary } \\
\mathrm{ADLs}\end{array}$ & $\begin{array}{l}\text { ORequifes assistance with } \\
\text { ADLs }\end{array}$ & Dlindependent with ADLs \\
\hline $\begin{array}{l}\text { DPt dependent on stafif and } \\
\text { astisted derices'for toileting }\end{array}$ & $\begin{array}{l}\text { OUsas aniinted dewica for } \\
\text { toilating independantly. }\end{array}$ & $\begin{array}{l}\text { Dlindperdent with toleting } \\
\text { without assisted dericas. }\end{array}$ \\
\hline $\begin{array}{l}\text { DBedrest, chair fast of } \\
\text { immobile, } 2 \text { person asaist }\end{array}$ & $\begin{array}{l}\text { D! person assist with } \\
\text { mobilization }\end{array}$ & $\begin{array}{l}\text { Oledependent with } \\
\text { mobilization (waller } \\
\text { includad) }\end{array}$ \\
\hline $\begin{array}{l}\text { QDFendent on balth case } \\
\text { providen for tuming and } \\
\text { fepositioning }\end{array}$ & $\begin{array}{l}\text { alpt reytires assistance with } \\
\text { tuming and repositioning }\end{array}$ & D Pt able to reposition salf \\
\hline Dlaolation fequing PpE & ORevestisolation & DNoisolation \\
\hline
\end{tabular}

DO NOT DUPLICATE WITHOUT PERIISSION

\section{B- COMPLEXITY*}

\begin{tabular}{|c|c|c|}
\hline $\begin{array}{l}\text { Lerel 1(at least2 of the criteria; } \\
\text { if only one criteria then pt is } \\
\text { level 2) }\end{array}$ & $\begin{array}{l}\text { Level 2 (atleast2 of the criteria OR } \\
\text { ouly one in level } 1 \text { \& one in level } 2 \text { ) }\end{array}$ & Letel 3 \\
\hline 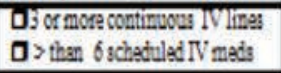 & D2 106 scheduled IV meds & $\begin{array}{l}\text { D! orzolv lisa } \\
\text { D0 - lachadulad IV mad }\end{array}$ \\
\hline $\begin{array}{l}\text { Ptis receiving on nertshift: } \\
\text { Q Cheno neding premeds and } \\
\text { close Monitoring* } \\
\text { QPush cheno } \\
\text { QNew sgent protocol } \\
\text { Q. } 2 \text { chemo on seme shitt }\end{array}$ & $\begin{array}{l}\text { Ptis receiring on next shift: } \\
\text { DOne or two IV chemo ou same dyy } \\
\text { DIT chemo } \\
\text { Q Subut chenno* }\end{array}$ & $\begin{array}{l}\text { Ptis receining ou nertshift: } \\
\text { QNo IV cheno } \\
\text { QPO cheno }\end{array}$ \\
\hline $\begin{array}{l}\text { Q4 or more blood products } \\
\text { a Blood product requiring } \\
\text { fequant monitoring (ieING) } \\
\text { Q Day 0 of Allo or Auto SCT }\end{array}$ & $\begin{array}{l}\text { Q2.3blood products besed on ifg of } \\
\text { platelet levels }\end{array}$ & $\begin{array}{l}\text { ONo Blood products or } \\
1 \text { blood product }\end{array}$ \\
\hline $\begin{array}{l}\text { D Pain fequining continnus } \\
\text { narcotic infusion", IV or SC inj. }\end{array}$ & $\begin{array}{l}\text { QC ontrollad pein with schediad and } \\
\text { / of breakthrough oral medications }\end{array}$ & GNopain \\
\hline 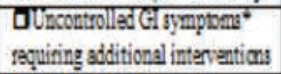 & $\begin{array}{l}\text { DControllad Gi symptoms with } \\
\text { schadulad intervantions }\end{array}$ & $\begin{array}{l}\text { ONo G symptoms" of no interventions } \\
\text { nasdad }\end{array}$ \\
\hline $\begin{array}{l}\text { DIGGPEGConimous of } \\
\text { Intemittent Feds }\end{array}$ & QIPN & 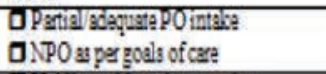 \\
\hline DPtrequiring dialyzis or CBI & $\begin{array}{l}\text { DHa scheduled bladder scanning } \\
\text { Dindrelling or intemitent cath }\end{array}$ & DVoding without intervention \\
\hline $\begin{array}{l}\text { DStages and 4 wounda } \\
\text { QNert Day shift : Pt requining } \\
\text { ertensive akin and round care* }\end{array}$ & 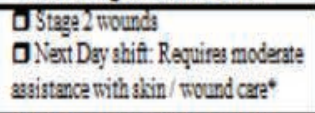 & $\begin{array}{l}\text { OStrage nourd requing minimal } \\
\text { assistace or no wound }\end{array}$ \\
\hline 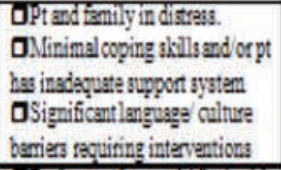 & 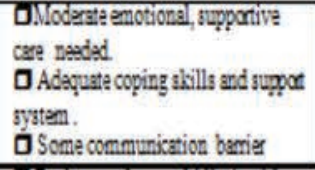 & $\begin{array}{l}\text { DPt and fanily zot indistreas. } \\
\text { QGood suppot sysem } \\
\text { QNo communicatim berie }\end{array}$ \\
\hline 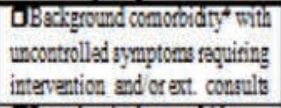 & $\begin{array}{l}\text { D Background comorbidry" with } \\
\text { controllad oymptoms and requiring } \\
\text { intervantions }\end{array}$ & $\begin{array}{l}\text { QNo comobidify or comorbidity not } \\
\text { requiring intervations }\end{array}$ \\
\hline $\begin{array}{l}\text { OProcedure in the nert } 24 \mathrm{kng} \\
\text { secuing } 015 \text { min-krmonitoring }\end{array}$ & $\begin{array}{l}\text { OProcedure in tha sart } 24 \text { las } \\
\text { secuing Q2hrs monitoring }\end{array}$ & $\begin{array}{l}\text { QNoprocedure in tha nest } 24 \mathrm{hrat} \\
\text { sequiring moxitong }\end{array}$ \\
\hline $\begin{array}{l}\text { QUPHQBARS } \\
\text { DCBGQD }\end{array}$ & $\begin{array}{l}\text { DBDblood wod } \\
\text { DCBGBD }\end{array}$ & DDaly bloodroch \\
\hline
\end{tabular}

\section{C- PREDICTABחITY}

\begin{tabular}{|c|c|c|}
\hline Level l(one of the following) & Level 2 ( one of the following ) & Level 3 \\
\hline 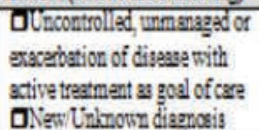 & $\begin{array}{l}\text { DPt improving on trestment } \\
\text { QMenaging gt syymtoms and } \\
\text { gaponse to treatment (chemo or } \\
\text { trangplant) }\end{array}$ & 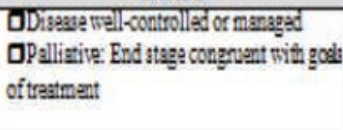 \\
\hline ONo dischergeplanned & $\begin{array}{l}\text { Olobadichaged within } \\
72 \mathrm{hs}\end{array}$ & $\begin{array}{l}\text { Olo be dichargen within } \\
24 \mathrm{~kg}\end{array}$ \\
\hline
\end{tabular}


the model to a hematology unit represents pioneering work and offers a tool and methodology that can be used in other patient populations. The limitations and challenges that we encountered can be ameliorated through various strategies that have been discussed. The flexible nature of the model is well suited to meeting the fluctuating acuity and needs of hematology/HSCT patients. The model enables healthcare administrators to make more informed, effective, real-time decisions about resource utilization and allocation in response to changes in patient acuity.

Finally, as CANO (2017) advocates: "the acuity level and complex needs of people with cancer require nurses to have a broad knowledge base." It is, therefore, important that both

\section{REFERENCES}

Benner, P. (1984). From novice to expert: Excellence and power in clinical nursing practice. Menlo Park: Addison-Wesley.

British Columbia Nurses Union. (2010). Provincial nursing workload project resource toolkit for teams: Nursing workload and staffing plan processes. Retrieved from https://www.bcnu.org/Safeworkplace/DefendProfessionalPractice/Documents/pnwp_ resource_toolkit.pdf

Canadian Association of Nurses in Oncology. (2017). Rationale for Standards of care. Retrieved from http://www.cano-acio.ca/page/ standards_of_care

Canadian Association of Nurses in Oncology. (2002). Practice standards and competencies. Retrieved from http://www.cano-acio.ca/conep.

Carter, K.F., \& Burnette, H.D. (2011). Creating patient-nurse synergy on a medical-surgical unit. Medsurg Nursing, 20, 249-254.

Curley, M.A. (Ed.). (2007). Synergy: The unique relationship between nurses and patients. Indianapolis: Sigma Theta Tau International.

Curley, M.A. (1998). Patient-nurse synergy: Optimizing patient's outcomes. American Journal of Critical Care, 7, 64-72.

Gralton, K.S. \& Brett, S.A. (2012). Integrating the synergy model for patient care at Children's Hospital in Wisconsin. Journal of Pediatric Nursing, 27, 7481. patients' needs and nurses' competency be measurable in order to provide the best match that will optimize the care provided. The developed hematology patient acuity tool and nurse competency tool will allow oncology units to provide a better fit between the needs of their patients and nursing competency providing the care.

\section{ACKNOWLEDGEMENTS}

We would like to thank our project team, the staff and physicians of the hematology/HSCT unit and the Juravinski Cancer Centre Foundation and F. Hoffmann-La Roche Ltd., who provided funding and support for this pilot project.

Hertel, R. (2012). Regulating patient staffing: A complex issue. MedSurg Matters, 21(1), 3-7.

Kaplow, R., \& Reed, K. (2008). The AACN synergy model for patient care: A nursing model as a force of magnetism. Nursing Economics, 26, 1725.

Kerfoot, K.M., Lavandero, R., Cox, M., Triola, N., Pacinin, C., \& Hanson, D.M. (2006). Conceptual models and the nursing organization. Implementing the AACN synergy model for patient care. Nurse Leader, 2026.

MacPhee, M., Wardrop, A., Campbell, C., \& Wejr, P. (2011). The synergy professional practice model and its patient characteristics tool: A staff empowerment strategy. Nursing Leadership, 24, 4255.

MacPhee, M.K., Jewell, K., Wardrop, A., Ahmed, A., \& Mildon, B. (2010). British Columbia's provincial nursing workload project: Evidence to empowerment. Canadian Journal of Nursing Leadership, 23, 5463.

Pope, B. (2002). The synergy matchup. Nursing Management, 33, 3841. 